\title{
ARTICLE
}

Clinical nutrition

\section{Continuous feeding versus intermittent bolus feeding for premature infants with low birth weight: a meta-analysis of randomized controlled trials}

\author{
Yan Wang $\mathbb{1}^{1,2} \cdot$ Wei Zhu² $\cdot$ Bi-ru Luo ${ }^{1}$
}

Received: 26 June 2019 / Revised: 7 October 2019 / Accepted: 14 October 2019 / Published online: 28 October 2019

(c) The Author(s), under exclusive licence to Springer Nature Limited 2019

\begin{abstract}
Background/objectives Clinical risks and advantages of both continuous feeding and intermittent feeding for preterm infants have been presented in previous studies. To determine the most appropriate feeding method for low-birth-weight infants, a meta-analysis was conducted.

Subjects/methods Articles related to this topic were searched in PubMed, EMBASE, and Cochrane Library electronic database from the onset to May 2019. Heterogeneity analysis was performed with Chi-square and $I^{2}$ test. Pooled analysis was based on fixed effects model, if heterogeneity between the eligible studies was negligible $\left(I^{2}<50 \%, P>0.05\right)$. In contrast, a random effects model was carried out. The quality of including studies were evaluated by Cochrane assessment tool.

Results A total of 1030 articles identified. Altogether, eight articles including 707 infants were included in final analysis based on eligibility criteria. In continuous feeding infants, time to achieving full feeds was longer (weight mean difference 0.98 (95\% CI 0.26-1.71, $P=0.008$ ) days) compared with intermittent feeding infants. Pooled analysis indicated there were no significant difference in other variables such as feeding intolerance, duration of hospitalization, days to regain birth weight, days to first successful oral feeding, duration of parenteral feeding, weight growth, length increment, head circumference growth, proven necrotizing enterocolitis, and probable necrotizing enterocolitis. In subgroup analysis for birth weight $(<1000 \mathrm{~g}$ and $>1000 \mathrm{~g})$, we did not identify significant difference in time to full feeds, time to regain birth weight, and duration of hospitalization.

Conclusions Intermittent feeding may be more beneficial for low-birth weight infants, However, well-designed studies and evidenced-based clinical practice are required to determine the most appropriate feeding method for premature infants with low birth weight.
\end{abstract}

\section{Introduction}

Enteral nutrition is the preferred nutrition method for infants in neonatal intensive units [1]. Nasogastric or orogastric tubes are used before infants can be fed orally. Only from approximately 32 weeks age or $1500 \mathrm{~g}$ body weight, infants

Bi-ru Luo

hxnurs@163.com

1 Key Laboratory of Birth Defects and Related Diseases of Women and Children, Sichuan University, Ministry of Education, West China Second University Hospital, Sichuan University, Chengdu, China

2 West China School of Nursing, Sichuan University, Chengdu, China are able to coordinate sucking, swallowing, and breathing and the danger of aspiration, allowing drinking milk without danger [2]. Generally, tube feeding consists of continuous feeding and intermittent bolus feeding. Continuous feeding is defined as delivering enteral nutrition with constant speed for $24 \mathrm{~h}$ via nutritional pump [2, 3]. Intermittent bolus feeding is defined as delivering enteral nutrition multiple times [4], generally giving $15-30 \mathrm{~min}$ every $2-3 \mathrm{~h}$ by gravity or electric pump.

Previous studies have found that both continuous feeding and intermittent bolus feeding have benefits and risks for preterm infants. On the one hand, continuous feeding can maintain the gastrointestinal hormonal such as gastrin and insulin at a high level [5], leading to the increase of absorption and reduction of energy expenditure [6]. On the other hand, continuous infusion of milk into the infant's 
gastrointestinal tract may lead to disorders of gastrointestinal hormones and long-term growth inhibition. A study on animal models suggested that continuous feeding, comparing with intermittent bolus feeding, reduces glucagon like peptide-1, which may contribute to organ dysfunction [7]. In addition, the incidence of prolonged apnea and apnea related hypoxia diseases such as retinopathy [8] in continuous feeding is significantly higher than that in intermittent feeding [5]. Regarding to intermittent bolus feeding, it was thought to more physiologic [9], making infants have cyclical surges of gastrin, gastric inhibitory peptide, and insulin, therefore, promoting the gastrointestinal tract development [9]. Moreover, intermittent feeding allows more parental involvement in feeding [10] and splanchnic perfusion [11]. Moreover, intermittent feeding promotes protein synthesis and improves the whole body's protein balance $[12,13]$, which play an important role in regulating nutritional disorders in infants. However, for premature infants, intermittent milk feeding may lead to feeding intolerance because it is easy for infants to exceed the absorbed capacity of their gastrointestinal tract with bolus milk infusion. Intermittent feeding also has been reported to be associated with metabolic instability [14] and impaired pulmonary functions [15] in preterm infants.

To compare the effect of continuous versus intermittent enteral feeding on low-birth weight infants, some studies were carried out [6, 10, 11, 16-18]. However, these studies did not reach an agreement. In 2011, Premji and Chessell [19] conducted a meta-analysis of seven randomized and quasi-randomized studies and found that it was inadequate for determining a preferred feeding method because of some limitations, such as small sample size and the inclusion of quasi-randomized studies. Therefore, now it is time for an update as larger, well designed studies reported on the effect of continuous feeding and intermittent feeding in preterm infants have appeared after 2011 [10, 11, 20, 21]. The objective of this meta-analysis was to determine the clinical risks and benefits of each method and help clinicians choose appropriate feeding strategy.

\section{Materials and methods}

\section{Search strategy}

To identify the studies on the effects of continuous feeding versus intermittent bolus feeding on premature infant with low birth weight, we used Mesh terms, keywords, and truncation symbol in the search strategy. And we searched electronic databases including PubMed, EMBASE, and Cochrane Library as following search term: (()(randomized controlled trial [pt] OR randomized controlled trials [mh] OR random allocation [mh] OR random allocat* [tw] OR randomly allocat* [tw] OR double-blind method[mh] OR single-blind method[mh] OR double blind* [tw] OR single blind [tw] OR triple blind* [tw] OR clinical trial [pt] OR clinical trials[mh])) AND Humans[Mesh])) AND ((((("ICU”[Title/Abstract]) OR "Intensive Care Units”[Mesh])) AND ((((“continuous enteral nutrition”[Title/ Abstract] OR “continuous tube feeding"[Title/Abstract] OR “continuous feeding"[Title/Abstract] OR "continuous infusion of enteral nutrition"[Title/Abstract]))) OR "Enteral Nutrition"[Mesh])) AND Humans[Mesh]). The search strategy was adjusted in accordance with each database. The published date of the studies was from the onset of the database to May 2019.

\section{Eligibility criteria}

(1) The participants were preterm infants (gestational age $<37$ weeks) with low birth weight (birth weight $<2500 \mathrm{~g}$ ).

(2) The type of studies was randomized control trial published in English. Quasi-experimental trial, cohort study, review, and commentary were excluded.

(3) The interventions were continuous feeding (nasogastric tube or orogastric tube, breast milk or formula milk) and intermittent feeding (nasogastric tube or orogastric tube, breast milk or formula milk). Broadly, continuous feeding can be considered as by using electric infusion pump. Intermittent feeding can be given by gravity or electric infusion pump and had a break in their feedings. The total feeding amounts should be same in the study group and control group. The outcomes were measured at the same time point.

(4) The outcomes were feeding intolerance, days to attain full enteral feeds, days to regain birth weight, days to first successful oral feeding, time to discharge (days), duration of supplement parenteral nutrition, somatic growth indexes including weight growth, length growth and head circumference, and necrotizing enterocolitis (NEC) including suspected and confirmed (Bell's Stage II or greater). Feeding intolerance was defined as gastrointestinal complications such as residual gastric volume, diarrhea, vomiting, and hematochezia during enteral nutrition.

\section{Study selection}

We identified studies related to the topic by reading the titles and abstracts. Then, we reassessed the potentially eligible studies by reading the full text, and excluded irrelevant articles according to eligibility criteria. All assessment was conducted independently by two reviewers 


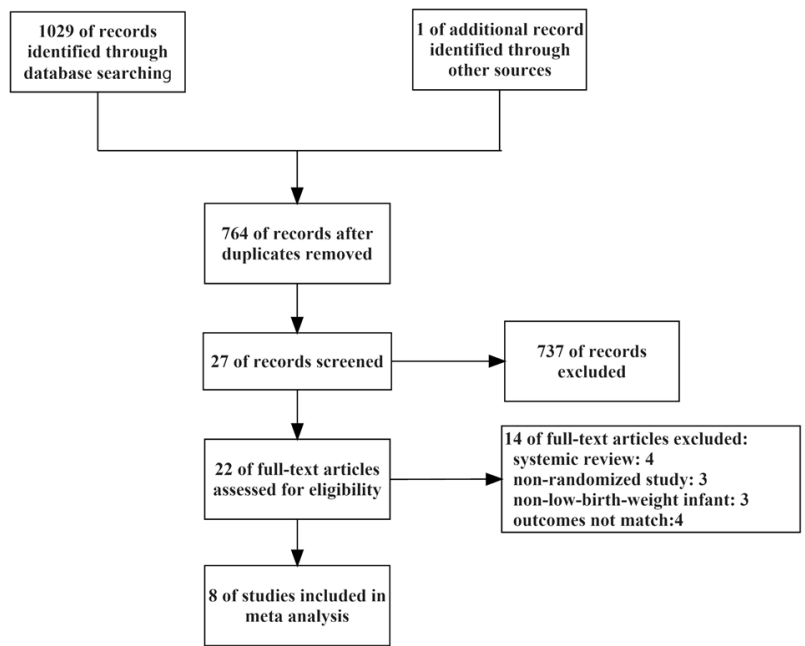

Fig. 1 Flow diagram of the search results

(YW and WZ). If there were disagreement for the exclusion and inclusion, the issue was discussed until consensus was reached by the reviewers.

\section{Data extraction}

Data extraction was conducted by YW and WZ independently. The following data were extracted: study design, publication year, location, demographic characteristics of subjects (especially gestational age and birth weight of infants), intervention methods, outcomes, and potential risk of bias. For quantitative data, the mean values and standard deviations (SD) were extracted. We used the equation from Cochrane handbook to merge mean value and SD of two groups if need it. Median and interquartile range were converted to mean value and SD using an online calculator (http://www.comp.hkbu.edu.hk/ xwan/median2mean.

html). For qualitative data, the number of cases of each study were extracted.

\section{Risk of bias assessment}

The qualities of the included studies were evaluated by Cochrane assessment tool. All studies were evaluated according to follow criteria: [1] random assigned, [2] allocation concealment, [3] blinding (participants, personnel, and outcome assessment), [4] incomplete outcome data, [6] selective reporting, and [7] other bias by two independent investigators. Each criterion must be classified as "low risk", "unclear", or "high risk".

\section{Statistical analysis}

We used Rev Man software version 5.3 to conducted the meta-analysis. Meta-analysis for dichotomous data was evaluated with risk ratio (RR) with $95 \%$ confidence interval (CI), and continuous variables were analyzed by weight mean difference (MD) with 95\% CI. Statistical heterogeneity was assessed by $\chi^{2}$ analysis and $I^{2}$ test. Fixed effects model was used when there was no obvious heterogeneity $\left(I^{2}>50 \%, P<0.05\right)$. In contrast, a random effects model was carried out. We planned to conduct subgroup analysis for birth weight and gestational age of outcome. Publication bias was evaluated by funnel plots.

\section{Results}

\section{Study selection and characteristics}

The descriptions of included and excluded studies were presented in Fig. 1. Through a comprehensive search in PubMed, EMBASE, and Cochrane Library, a total of 1029 studies were identified, and one of additional records was identified through other sources. In total, 266 articles were removed as they were duplication of the same report. After screening the titles and abstracts, we excluded 737 records as they were irrelevant to the topic of this study and five records as their full texts were not available. Fourteen studies were excluded and eight studies were included after rereading the full text for the following reasons: articles were reviews or systematic review [19, 22-24]; the study design were not randomized control trails [6, 25, 26]; the subjects were not low-birth-weight infants [27-29]; the primary outcome were not matched [11, 30-32].

Altogether, a total of eight studies including 707 infants were included in this research. Table 1 summarized the main features of the eight studies. One article was the conference abstract, which we included because it described the methods and results detailly [20]. The eight articles were published between 1992 and 2018. Four studies conducted randomized-controlled trail and compared multiple study groups [18, 20, 33, 34]. Four studies did not describe the detailed intervention methods about the duration of continuous feeding $[17,20,33,34]$ and one study did not describe the duration of intermittent feeding [34].

\section{Risk of bias within studies}

The detailed risk of bias for each study was displayed in Fig. 2a, and the summary of the risk of bias was presented in Fig. $2 b$.

\section{Quantitative synthesis of data}

We analyzed the effects of the feeding methods on infants from the aspects of feeding performance, somatic growth, utilization of medical resources, feeding tolerance, and 


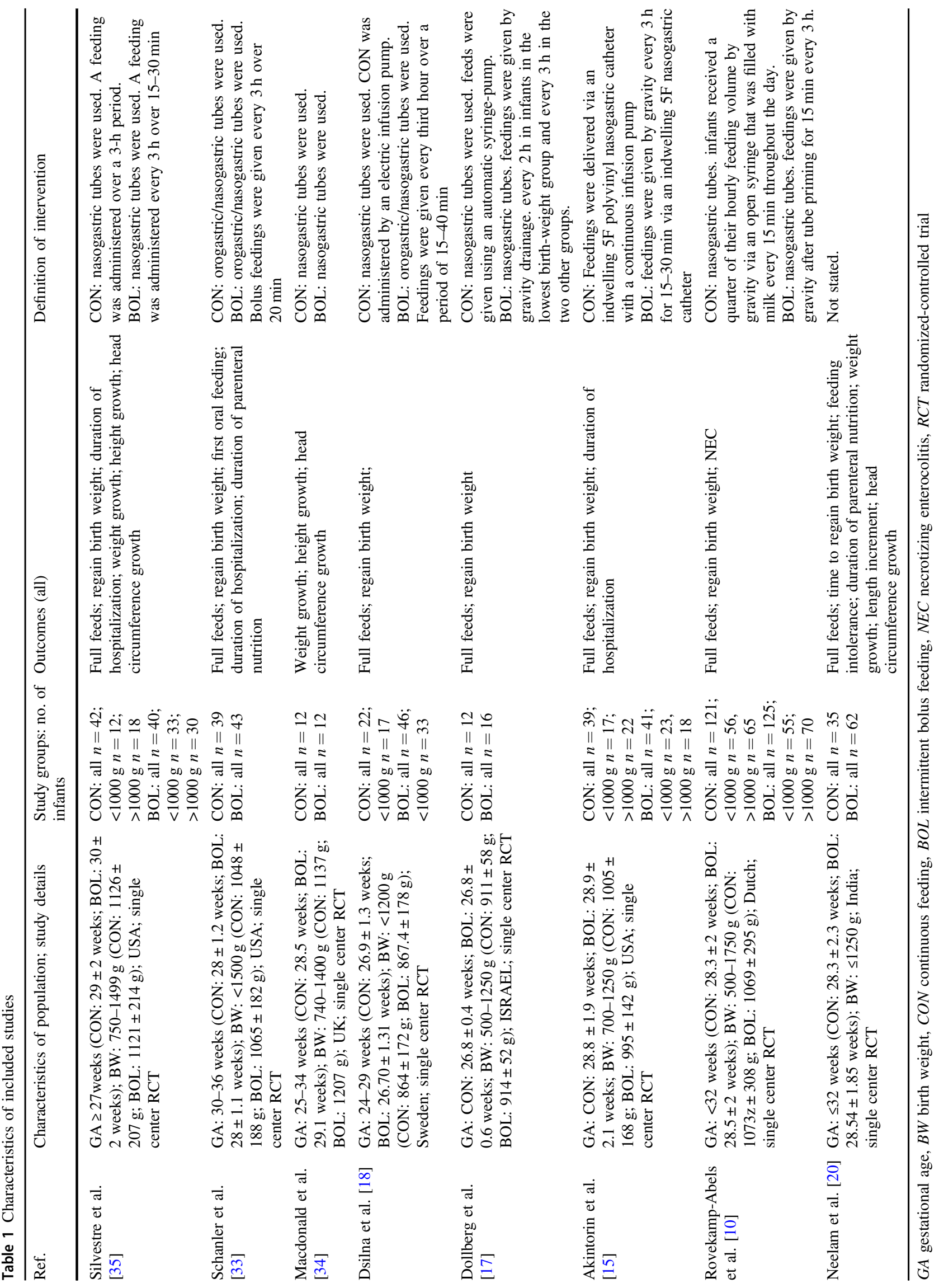


Fig. 2 Risk of bias: risk of bias

in individual trials (a) and summary of brisk of bias of included studies (b)
A

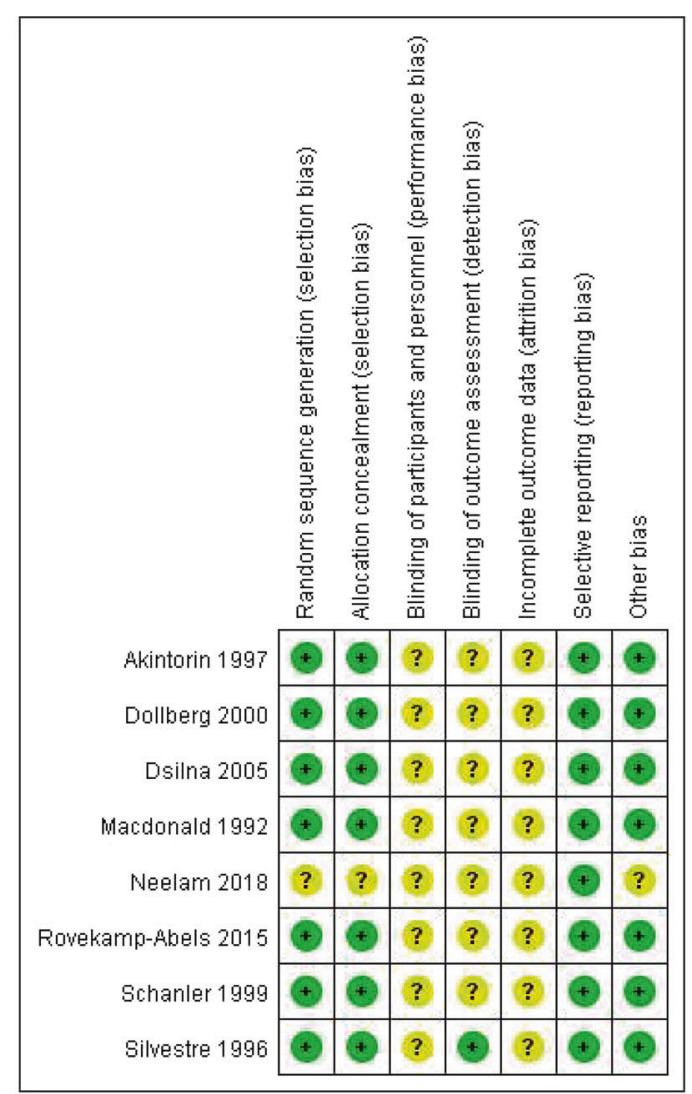

B

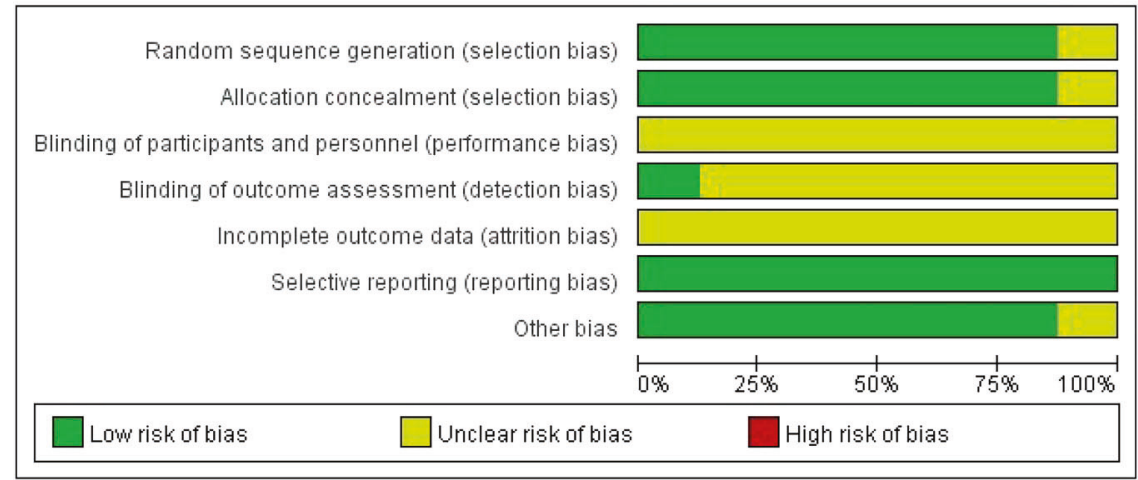

complication of feeding methods. In this study, feeding performance mainly included five outcomes: days to full enteral feeds, days to regain birth weight, days to first successful oral feeding, duration of hospitalization, and duration of supplement parenteral nutrition. The weight mean difference of days to full enteral feeds was 0.98 (95\% CI $0.26-1.71, P=0.008$ ) days in all infants (Table 2). No significant weight mean difference in other four variables were found between continuous feeding group and intermittent bolus feeding group of all infants. In somatic growth, we did not detect the significant difference in weight growth, length increment, and head circumference growth. As well, no significant were detected in utilization of medical resources (duration of hospitalization), feeding intolerance, and complication (proven or probable NEC).

We conducted subgroup analysis for birth weight of outcomes. A total of four studies were included $[10,15,18,35]$. All infants were divided into groups of $<1000 \mathrm{~g}$ and $>1000 \mathrm{~g}$. However, in subgroup analysis and pooled analysis, we did not find significant difference in days to full enteral feeds, regain birth weight, and duration of hospitalization. The weight mean difference of days to full enteral feeds were $0.63(95 \% \mathrm{CI}-0.49,1.76, P=0.27)$ days in groups of $<1000 \mathrm{~g}, 0.26(95 \% \mathrm{CI}-0.39,0.90$, $P=0.44$ ) days in groups of $>1000 \mathrm{~g}$ (Fig. 3). The weight mean difference of regain birth weight were -3.07 (95\% CI 
Table 2 Continuous feeding versus intermittent bolus feeding-all infants

\begin{tabular}{|c|c|c|c|c|c|c|c|}
\hline Outcome & Studies $(n)$ & Participants $(n)$ & Effect size & $Z$ & $I^{2}$-value $(\%)$ & Model & Study reference \\
\hline Feeding intolerance & 2 & 177 & $0.91[0.65-1.27]$ & 0.55 & 0 & Fixed & {$[16,31]$} \\
\hline Full enteral feeds (days) & 6 & 655 & $0.98[0.26-1.71]$ & $2.66^{* *}$ & 44 & Fixed & {$[11,14,16,28,30,31]$} \\
\hline Regain birth weight (days) & 7 & 678 & $-0.41[-1.03,0.21]$ & 1.29 & 0 & Fixed & {$[11,12,14,16,28,30,31]$} \\
\hline $\begin{array}{l}\text { First successful oral } \\
\text { feeding (days) }\end{array}$ & 2 & 179 & $0.70[-8.54,9.95]$ & 0.15 & 0 & Fixed & {$[16,28]$} \\
\hline $\begin{array}{l}\text { Duration of } \\
\text { hospitalization (days) }\end{array}$ & 3 & 244 & $-1.67[-6.32,2.98]$ & 0.70 & 0 & Fixed & {$[28,30,31]$} \\
\hline $\begin{array}{l}\text { Duration of parenteral } \\
\text { feeding (days) }\end{array}$ & 2 & 179 & $-0.58[-2.75,1.60]$ & 0.50 & 0 & Fixed & {$[16,28]$} \\
\hline Weight growth (g/week) & 2 & 106 & $-0.58[-2.75,1.60]$ & 1.63 & 0 & Fixed & {$[29,30]$} \\
\hline Length increment (cm/week) & 3 & 203 & $-0.58[-2.75,1.60]$ & 0.15 & 16 & Fixed & {$[16,29,30]$} \\
\hline $\begin{array}{l}\text { Head circumference }(\mathrm{cm} / \\
\text { week) }\end{array}$ & 3 & 203 & $0.17[-0.18,0.52]$ & 0.94 & 98 & Random & {$[16,29,30]$} \\
\hline $\begin{array}{l}\text { Proven NEC (Bell's Stage II } \\
\text { or greater) }\end{array}$ & 4 & 418 & $1.03[0.45,2.38]$ & 0.08 & 0 & Fixed & {$[11,14,29,31]$} \\
\hline Probable NEC & 3 & 127 & $2.30[0.73,7.32]$ & 1.42 & 0 & Fixed & {$[12,29,31]$} \\
\hline
\end{tabular}

NEC necrotizing enterocolitis

${ }^{* *} P<0.01$

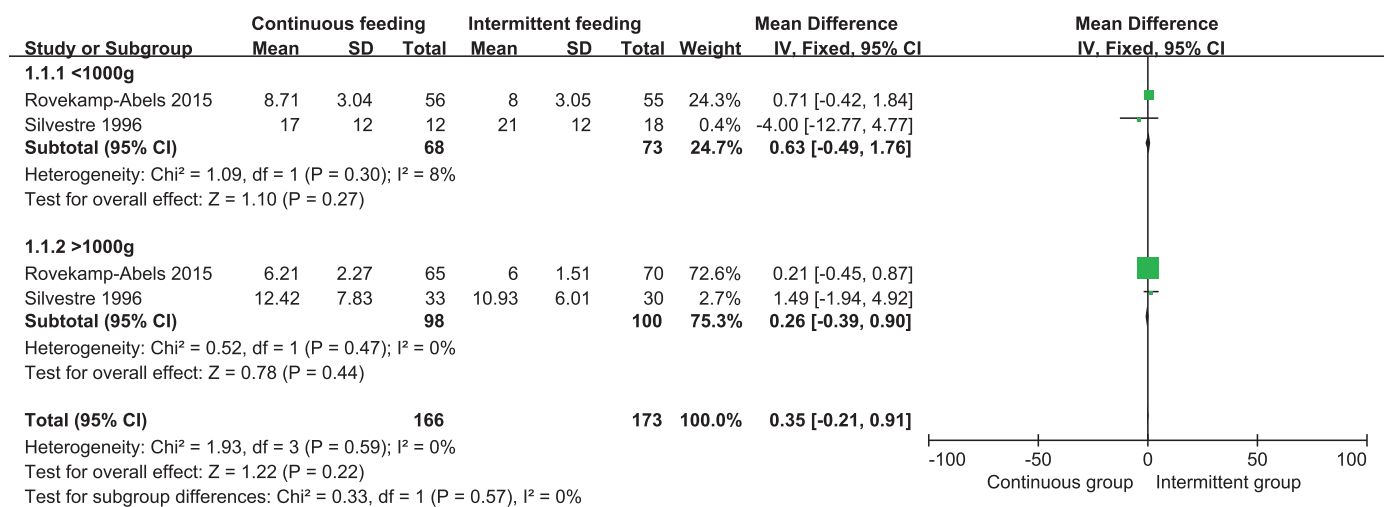

Fig. 3 Pooled weight mean difference in time to achieve full feeds between the continuous feeding group and intermittent feeding group

$-8.97,2.84, P=0.31)$ days in groups of $<1000 \mathrm{~g},-0.90$ (95\% CI $-1.91,0.12, P=0.08$ ) days in group of $>1000 \mathrm{~g}$ (Fig. 4). The weight mean difference of duration of hospitalization were $-4.52(95 \% \mathrm{CI}-15.12,6.09, P=0.40)$ days in groups of $<1000 \mathrm{~g}, 0.62(95 \% \mathrm{CI}-2.30,3.54, P=$ 0.68 ) days in group of $>1000 \mathrm{~g}$ (Fig. 5).

\section{Discussion}

The results of this meta-analysis showed that continuous feeding needs more days to achieve full feeds compared with intermittent feeding in low-birth-weight infants. For reducing nursing time and medical costs, we thought that intermittent feeding may have more benefit for low-birth weight infants according to current evidence synthesized from randomized-controlled trials, although it was at low level.

In this meta-analysis, we found that continuous group need more days to achieve full feeds compared with intermittent group for all infants, which was consistent with some studies [15, 33-35]. However, our results were different from Dsilna's [18] findings, which displayed that continuous feeding infants achieve full feeds faster than intermittent feeding infants $\quad(\mathrm{aHR}=1.84, \quad 95 \% \quad \mathrm{CI}$ 1.03-3.27), especially in infants with birth weight $\leq 850 \mathrm{~g}$ (aHR $=4.13,95 \%$ CI 1.48-11.53). A retrospective study conducted by Rojahn [36] also showed that continuous group had fewer days to attain full feeds. One reason for this difference may be that the characteristics of subject such as birth weight and gestational age were different. Dsilna [18] focused on infants with birth weight $<1200 \mathrm{~g}$ and 


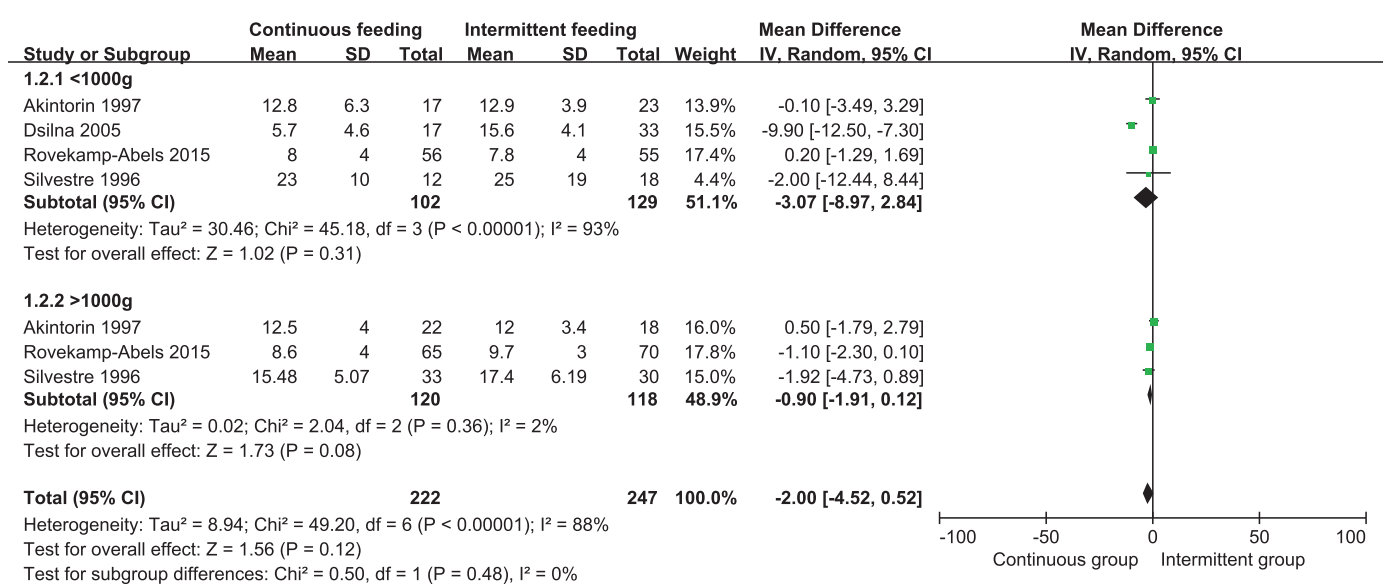

Fig. 4 Pooled weight mean difference in time to regain birth weight between the continuous feeding group and intermittent feeding group

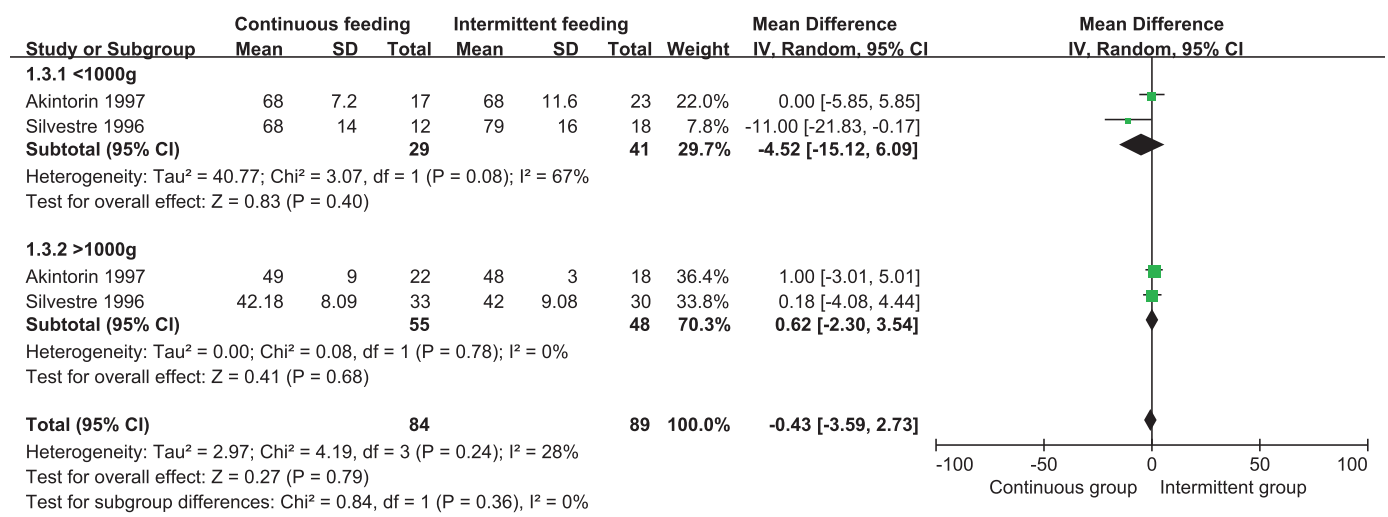

Fig. 5 Pooled weight mean difference in duration of hospitalization between the continuous feeding group and intermittent feeding group

gestational age between 24 and 29 weeks. Other studies mainly focused on larger birth weight infants [10, 33]. Moreover, the feeding protocol including milk composition, starting time of enteral nutrition, and the daily increase of milk volume was different. We did not find significant difference of time to achieve full feeds in subgroup analysis for birth weight. The reason may be that only four studies included in subgroup analysis and the sample size was too small. The finding in our study suggested that intermittent bolus feeding was more preferable for infants in terms of decreasing time to attain full enteral feeds. However, further research is needed on which feeding methods are more beneficial for infants of different gestational age and birth weight.

In this study, we did not find significant difference in feeding intolerance, time to regain birth weight, time to attain first successful oral feeding, duration of hospitalization, duration of parenteral feeding, etc. (Table 2) in pooled analysis. In subgroup analysis, we also did not detect significant difference in time to attain full feeds, time to regain birth weight, and duration of hospitalization. The reason may be that the sample size was insufficient. In addition, the interference from other treatments for premature infants such as invasive or noninvasive ventilator support and prolonged parenteral nutrition may contribute to these results. Another reason for these results is that many preterm infants had severe disease, which may affect their nutritional status.

Pooled analysis is known to have some limitations, resulting from the combination of studies with different feeding protocol, different definitions of outcomes, and different study population. The inconsistence of the feeding protocols of included studies is an example of this issue. In this study, four studies did not state the strategy of continuous feeding strategy or intermittent feeding $[17,20,33,34]$. Most studies started enteral feeding on the second to fourth day after birth [17, 33-35]. Only two studies started enteral nutrition within $30 \mathrm{~h}$ postnatal age [10, 18]. A recent review [37] proposed a reasonable strategy to optimize enteral feeding practice, in which the first feeding time should be started between 6 and $48 \mathrm{~h}$ of life, to avoid gastrointestinal atrophy and dysfunction. The 
studies included in this meta-analysis were mostly breastfed (from their own mother) or formula-fed. Only one study used human milk feeding only, adding frozen pasteurized human milk from the local milk bank when the milk production of the mother was inadequate [18]. A detailed review [37] presented the large number of benefits of human milk for premature infants, and advocated donor human milk can be used alternatively when human milk was inadequate. In addition, the lack of uniformity of definition of the outcome index is another issue. For example, the full enteral feeds had different definitions in different studies. Schanler [33] and Macdonald [34] defined full feeds as achieving $150 \mathrm{ml} / \mathrm{kg} / \mathrm{day}$, and Dsilna [18] defined full feeds as attaining $140-160 \mathrm{ml} / \mathrm{kg} / \mathrm{day}$. Dollberg [17] and Roverkamp-Abels [10] defined full feeds as achieving $160 \mathrm{ml} / \mathrm{kg} / \mathrm{day}$ and $120 \mathrm{ml} / \mathrm{kg} /$ day, respectively. Akintorin [15] defined full feeds as the ability to tolerate enteral feedings of $100 \mathrm{kcal} / \mathrm{kg} / \mathrm{day}$ for at least $48 \mathrm{~h}$. Furthermore, the measure time points were different in each study. In some studies [15, 33], researchers measured gastric residual every 2 or $3 \mathrm{~h}$ to maintain consistency with feeding intervals, and another part of studies [10, 18] measured gastric residual every $6-8 \mathrm{~h}$, which in line with the physiological characteristics of gastrointestinal activity in infants. Birth weight, height, head circumference, and other somatic growth indicators measured daily [35] or weekly [34].

Only randomized-controlled trials included in this metaanalysis. As we all known, randomized-controlled trials were of the highest quality evidence according to Grade guideline [38]. Our synthesis results are more indicative the efficacy of continuous feeding and intermittent feeding on infants compared with previous systematic review [23]. In addition, we selected several outcomes to evaluate the impact of the two feeding strategies on infants from five aspects, including feeding performance, somatic growth, utilization of medical resources, feeding tolerance, and complications. Our study had several limitations. First, gestational age was an additional significant variable. Nevertheless, we were unable to examine the effect of sex because there was none randomized-controlled trial reported outcomes by sex. Second, the type of gastric tube was another significant variable that we cannot detect its effect as only a limited number of studies reported outcomes by the type of gastric tube. Third, our study was short of evaluation of other aspects such as pulmonary function [28], splanchnic perfusion [11], and laboratory outcomes because a limited number of studies reported these outcomes.

This study found that continuous feeding group need more days to achieving full feed compared with intermittent feeding groups. Clinical professions can take intermittent bolus feeding as the preferred feeding method to reduce nursing time and medical costs. Further research should have clear definition of each outcome index, stratify the birth weight, gestational age, and illness of infants', and then to determine if either feeding strategy is more beneficial for preterm infants. In addition, multicenter large sample studies, especially randomized-controlled trials, are also essential for this topic.

Author contributions WZ contributed in study design, search, screening potentially eligible studies, and data extraction in this work. YW contributed in conception, screening potentially eligible studies, data extraction, data analysis, figures, and drafting the paper. BL contributed to drafting and editing the paper. All authors approved the final paper for submission.

\section{Compliance with ethical standards}

Conflict of interest The authors declare that they have no conflict of interest.

Publisher's note Springer Nature remains neutral with regard to jurisdictional claims in published maps and institutional affiliations.

\section{References}

1. Mangili G, Garzoli E. Feeding of preterm infants and fortification of breast milk. Pediatr Med Chir. 2017;39:158.

2. Valman HB, Heath CD, Brown RJ. Continuous intragastric milk feeds in infants of low birth weight. Br Med J. 1972;3:547-50.

3. Patel JJ, Rosenthal MD, Heyland DK. Intermittent versus continuous feeding in critically ill adults. Curr Opin Clin Nutr Metab Care. 2018;21:116-20.

4. Aynsley-Green A, Adrian TE, Bloom SR. Feeding and the development of enteroinsular hormone secretion in the preterm infant: effects of continuous gastric infusions of human milk compared with intermittent boluses. Acta Paediatr Scand. 1982;71:379-83.

5. Corvaglia L, Martini S, Aceti A, Capretti MG, Galletti S, Faldella G. Cardiorespiratory events with bolus versus continuous enteral feeding in healthy preterm infants. J Pediatr. 2014;165:1255-7.

6. Toce SS, Keenan WJ, Homan SM. Enteral feeding in very-lowbirth-weight infants: a comparison of two nasogastric methods. Am J Dis Child. 1987;141:439-44.

7. Marik PE. Feeding critically ill patients the right 'whey': thinking outside of the box. A personal view. Ann Intensive Care. 2015;5: UNSP 11.

8. Di Fiore JM, Bloom JN, Orge F, Schutt A, Schluchter M, Cheruvu VK, et al. A higher incidence of intermittent hypoxemic episodes is associated with severe retinopathy of prematurity. J Pediatr. 2010;157:69-73.

9. Lucas A, Bloom SR, Aynsleygreen A. Gut hormones and "minimal enteral feeding". Acta Paediatr Scand. 1986;75:719-23.

10. Rovekamp-Abels LW, Hogewind-Schoonenboom JE, de WijsMeijler DP, Maduro MD, Jansen-van der Weide MC, van Goudoever JB, et al. Intermittent bolus or semicontinuous feeding for preterm infants? J Pediatr Gastroenterol Nutr. 2015;61:659-64.

11. Bozzetti V, Paterlini G, De Lorenzo P, Gazzolo D, Valsecchi MG, Tagliabue PE. Impact of continuous vs bolus feeding on splanchnic perfusion in very low birth weight infants: a randomized trial. J Pediatr. 2016;176:86-92.e2. 
12. Gazzaneo MC, Suryawan A, Orellana RA, Torrazza RM, El-Kadi SW, Wilson FA, et al. Intermittent bolus feeding has a greater stimulatory effect on protein synthesis in skeletal muscle than continuous feeding in neonatal pigs. J Nutr. 2011;141:2152-8.

13. Bohe J, Low JF, Wolfe RR, Rennie MJ. Latency and duration of stimulation of human muscle protein synthesis during continuous infusion of amino acids. J Physiol. 2001;532(Pt 2):575-9.

14. Mizumoto H, Kawai M, Yamashita S, Hata D. Intraday glucose fluctuation is common in preterm infants receiving intermittent tube feeding. Pediatrics Int. 2016;58:359-62.

15. Akintorin SM, Kamat M, Pildes RS, Kling P, Andes S, Hill J, et al. A prospective randomized trial of feeding methods in very low birth weight infants. Pediatrics. 1997;100:E4.

16. Churella HR, Bachhuber WL, Maclean WC. Survey-methods of feeding low-birth-weight infants. Pediatrics. 1985;76:243-9.

17. Dollberg S, Kuint J, Mazkereth R, Mimouni FB. Feeding tolerance in preterm infants: randomized trial of bolus and continuous feeding. J Am Coll Nutr. 2000;19:797-800.

18. Dsilna A, Christensson K, Alfredsson L, Lagercrantz H, Blennow M. Continuous feeding promotes gastrointestinal tolerance and growth in very low birth weight infants. J Pediatr. 2005;147:43-9.

19. Premji SS, Chessell L. Continuous nasogastric milk feeding versus intermittent bolus milk feeding for premature infants less than 1500 grams. Cochrane Database Syst Rev. 2011;CD001819.

20. Neelam K, Vijay K, Pankaj G, Anup T. Comparison of continuous versus intermittent bolus feeding in preterm infants $\leq 32$ weeks and $\leq 1250$ g. J Paediatr Child Health. 2018;54:37-8.

21. Brown AM. A comparison of bolus versus continuous feeding methods in mechanically ventilated children. Crit Care Med. 2014;42 12 SUPPL 1:A1439.

22. Richards R, Foster JP, Psaila K. Continuous versus bolus intragastric tube feeding for preterm and low birth weight infants with gastro-oesophageal reflux disease. Cochrane Database Syst Rev. 2014;CD009719.

23. Premji S, Chessell L. Continuous nasogastric milk feeding versus intermittent bolus milk feeding for premature infants less than 1500 grams. Cochrane Database Syst Rev. 2003;CD001819.

24. Bozzetti V, Tagliabue PE. Enteral nutrition for preterm infants: by bolus or continuous? An update. Pediatr Med Chir. 2017;39:159.

25. Wells DH, Zachman RD. Nasojejunal feedings in low-birthweight infants. J Pediatr. 1975;87:276-9.
26. Brans YW, Andrew DS, Dutton EB, Menchaca EM. Lipids in plasma of enterally-fed very low-birthweight neonates. Am J Perinatol. 1987;4:160-3.

27. Rn MDH, Rn WC, Schluter PJ. Gastric residual volumes in critically ill paediatric patients: a comparison of feeding regimens. Aust Crit Care. 2004;17:98-103.

28. Lagrutta F, Castillo C. Early enteral feeding of infants with lower respiratory infections. Rev Chil Pediatr. 1991;62:167-73.

29. Grant J, Denne SC. Effect of intermittent versus continuous enteral feeding on energy expenditure in premature infants. J Pediatr. 1991;118:928-32.

30. Blondheim O, Abbasi S, Fox WW, Bhutani VK. Effect of enteral gavage feeding rate on pulmonary functions of very low birth weight infants. J Pediatr. 1993;122 5 Pt 1:751-5.

31. Dsilna A, Christensson K, Gustafsson AS, Lagercrantz H, Alfredsson L. Behavioral stress is affected by the mode of tube feeding in very low birth weight infants. Clin J Pain. 2008;24:447-55.

32. Becerra M, Cifuentes J, Saldfas MI, Gálvez MC, Fernández P, Aguila A. Continuous gastric drip versus intravenous fluids in low birthweight infants. Acta Paediatr. 2002;91:430-3.

33. Schanler RJ, Shulman RJ, Lau C, Smith EO, Heitkemper MM. Feeding strategies for premature infants: randomized trial of gastrointestinal priming and tube-feeding method. Pediatrics. 1999;103:434-9.

34. Macdonald PD, Skeoch CH, Carse H, Dryburgh F, Alroomi LG, Galea P, et al. Randomised trial of continuous nasogastric, bolus nasogastric, and transpyloric feeding in infants of birth weight under 1400 g. Arch Dis Child. 1992;67 4 Spec No:429-31.

35. Silvestre MA, Morbach CA, Brans YW, Shankaran S. A prospective randomized trial comparing continuous versus intermittent feeding methods in very low birth weight neonates. J Pediatr. 1996;128:748-52.

36. Rojahn A, Lindgren CG. Enteral feeding in infants $<1250 \mathrm{~g}$ starting within $24 \mathrm{~h}$ post-partum. Eur J Pediatr. 2001;160:629-32.

37. Senterre T. Practice of enteral nutrition in very low birth weight and extremely low birth weight infants. World Rev Nutr Diet. 2014;110:201-14.

38. Balshem H, Helfand M, Schuenemann HJ, Oxman AD, Kunz R, Brozek J, et al. GRADE guidelines: 3. Rating the quality of evidence. J Clin Epidemiol. 2011;64:401-6. 